experimental chamber, and responses were measured over the entire day rather than for a limited time, as in the present study. Within-day changes in levels of deprivation, related to time between meals, may have maintained responding in his study, whereas in this experiment, the session duration was less than the usual time between meals.

In the present study, the delivery of response-contingent food pellets was found to be essential to the maintenance of keypressing, yet the rats received only a small portion of their daily food intake by keypressing and could have obtained all of their food without pressing at all. They even pressed the key for food after continuous access to food for 8 days and ate all the pellets obtained by keypressing, but they ate little or no free food at all during these sessions. It is clear that the rats did not respond on the key to satisfy a nutritional need. Their regular stimulus-controlled alternation between free feeding and keypressing indicates that they also did not operate the key because of a preference for keypressing or for working. Their keypress behavior was strongly under conditioned stimulus control established during their training history. Further work is necessary to determine what other types of schedule performance persist under these conditions. In this study, the controlling stimulus could have been any or all of several elements of a stimulus complex, e.g., FR light, keypress response chain, or food delivery. This type of feeding behavior may be analogous to that seen in studies on conditioned hunger (e.g., Wright, 1965), paradoxical effects of satiation (e.g., Teel \& Webb, 1951), and certain types of human obesity (e.g., Schacter, 1968).

\section{REFERENCES}

BERKUN, M. M., KESSEN, M. L., \& MILLER, N. E. Hunger reducing effects of food by stomach fistula versus food by mouth measured by a consummatory response. Journal of Comparative \& Physiological Psychology, 1952, 45. $550-554$.

CARDER, B., \& BERKOWITZ, K. Rat's preference for earned in comparison with free food. Science, 1970, 167. $1273-1274$.

DAVIDSON, A. B., DAVIS, D. J., \& COOK, L. A rapid automatic technique for generating operant key-press behavior in rats. Journal of the Experimental Analysis of Behavior, 1971, 15, 123-127.

JANOWITZ, H. D., \& GROSSMAN, M. I. Some factors affecting food intake of normal dogs and dogs with esophagostomy and gastric fistulas. American Journal of Physiology, 1949 . $159,143-148$.

JENSEN, G. D. Preference for bar pressing over "freeloading" as a function of number of rewarded presses. Journal of Experimental Psychology, 1963,65. 451-454.
NEURINGER, A. J. Animals respond for food in the presence of free food Science, 1969,166,399-401.

NEURINGER、A. J. Many responses per food reward with free food present. Science, 1970, $169,503-504$.

SCHACTER, S. Obesity and eating. Science. $1968,161,751-756$.

SIDMAN, M., \& STEBBINS, W. C. Satiation effects under fixed-ratio schedules of reinforcement, Journal of Comparative \& Physiological Psychology, 1954, 47. 114-116.

TEEL, K., \& WEBB, W. B. Response evocation on satiated trials in the $T$-maze. Journal of Experimental Psychology $1951,41,148-152$.
WRIGHT, J. H. Test for a learned drive based on the hunger drive. Joumal of Experimental Psychology, 1965, 70. 580-584.

NOTES

1. Each time-out component terminated after a cessation of responding for 20 sec or after $1 \mathrm{~min}$ if no time-out interyesponse time had exceeded $20 \mathrm{sec}$ (but no sooner than 0.5 sec after a response)

2. Effects which deviated from the mean of each rat's performance on the three preceding control days by more than 4.3 standard deviations ( $2 \mathrm{df} ; \mathrm{p}<.05)$ were considered significant.

\title{
The differential effects of omission and extinction following DRL pretraining*
}

\author{
JEFF S. TOPPING, JOHN W. PICKERING, and JERRY A. JACKSON† \\ Mississippi State University, State College, Miss. 39762
}

The present study attempted to compare the response-elimination efficiencies of omission and extinction training following DRL 20-sec pretraining. Results indicated that omission training produced relatively more rapid and more complete response elimination than extinction training.

Previous attempts to eliminate responding have almost exclusively utilized either extinction or punishment training, or some combination of these two techniques. In addition, omission training, in which $S$ is reinforced for omitting a previously reinforced response, has also been shown to be a successful method of response elimination (Baer, Peterson, \& Sherman, 1967; Long, 1962, 1963; Mishkin \& Weiskrantz, 1959; Reynolds, 1961; Sherman, 1965). However, it has been just recently that any attempt has been made at assessing the relative efficacy of these response-elimination techniques.

Uhl \& Garcia (1969) investigated the response-elimination efficiency and durability of omission training (OT) and extinction training (ET). Their results indicated that ET produced slightly more rapid response elimination but that OT resulted in more durable effects. Similarly, Uhl \&

*Supported in part by National Science Foundation Institutional Grant for Science No. R 200J-4450.

+Requests for reprints should be sent to Jeff S. Topping, P.O. Drawer PF. Mississippi State University, State College, Miss. 39762.
Sherman (1971) compared combinations of OT, ET, and punishment and observed that response elimination was most rapid when punishment was combined with OT and ET, as opposed to either of the latter two techniques used in isolation. In addition, OT alone yielded longer lasting effects, as compared to ET alone or combinations of OT or ET with punishment.

It should be noted that both Uhl \& Garcia (1969) and Uhl \& Sherman (1971) used rats as Ss and employed a variable interval (VI) 30-sec schedule in their investigations of the various response-elimination procedures. The present experiment was designed to extend the comparison of OT and ET by means of two methodological variations: (1) pigeons were used as Ss, and (2) a differential reinforcement of low rate (DRL) 20-sec schedule was utilized as the pretraining reinforcement schedule. Since DRL schedules and OT are both instances in which the $S$ must learn to inhibit responding to produce reinforcement, it was hypothesized that this similarity might facilitate the responseelimination effectiveness of $\mathrm{OT}$, as opposed to ET. 
Table 1

Terminal DRL Responding

\begin{tabular}{rcc}
$\mathrm{S}$ & $\begin{array}{c}\text { Response } \\
\text { Rate } \\
\text { Per Min }\end{array}$ & $\begin{array}{c}\text { Percentage } \\
\text { Reinforced } \\
\text { Responses }\end{array}$ \\
\hline 2 & 8.86 & 1.11 \\
3 & 10.45 & 0.96 \\
14 & 9.92 & 0.84 \\
11 & 9.14 & 0.88 \\
12 & 9.83 & 1.08 \\
16 & 8.47 & 0.95 \\
\hline
\end{tabular}

\section{SUBJECTS}

Six experimentally naive male White King pigeons, individually housed, served as $\mathrm{Ss}$ and were maintained at approximately $75 \%$ of their free-feeding weights for a period extending from 1 week prior to the experiment through the duration of the experiment.

\section{APPARATUS}

A standard three-key pigeon chamber, $191 / 2 \times 14 \times 14$ in., was ventilated cubicle. The 1 -in.-diam keys were centered, $10 \mathrm{in}$. from the floor and 4 in. apart, on a metal panel separating the S's chamber from the area containing the stimulus- and food-presenting mechanisms. Only the center key was employed in the present experiment; the remaining keys were covered by metal plates. A minimum force of $15 \mathrm{~g}$ was required to operate the $\mathrm{key}$, and responses produced auditory feedback. A one-plane readout allowed white light to be projected on the response key, and the experimental chamber was diffusely lighted from above by two small lightbulbs. Three inches from the bottom of the intelligence panel was centered a $2 \times 2$ in. opening, through which a solenoid-operated grain hopper could be presented. Reinforcement consisted of a 5-sec access to the illuminated grain hopper. A blower functioned throughout the experiment to mask extraneous noises and to regulate the temperature inside the chamber. A system of automatic controlling and recording equipment allowed the data to be collected in a separate room.

\section{PROCEDURE}

As soon as Ss were reduced to $75 \%$ of their ad lib weights, they were given located within a sound-attenuating

2 days of magazine training, during which 50 reinforcements were delivered daily according to a noncontingent VI 20-sec schedule. Ss were then shaped (CRF) to peck the response key and allowed to make 50 continuously reinforced responses. On the next day, all Ss were switched to a DRL 4-sec schedule, and the DRL value was increased daily in 1-sec steps until a DRL 20-sec schedule was finally obtained. All of the sessions with the DRL schedules were terminated after $60 \mathrm{~min}$ or 50 reinforcements, whichever occurred first. All Ss received a total of 25 sessions on the DRL 20-sec schedule.

On the day following termination of DRL 20-sec pretraining, half of the six Ss were switched to OT and half to ET. The OT Ss had responsereinforcement and reinforcementreinforcement intervals of $20 \mathrm{sec}$; i.e., e a ch response postponed reinforcement for another $20 \mathrm{sec}$, and reinforcements occurred every $20 \mathrm{sec}$ if no responses were emitted. Ss received 10 days of either OT or ET, with OT sessions lasting $25 \mathrm{~min}$ or 50 reinforcements, whichever occurred first. Each of the ET Ss was yoked to one of the OT Ss and received a daily session equal in duration to his "partner's."

\section{RESULTS AND DISCUSSION}

Mean individual response rates and percentages of reinforced responses during the final 5 days of pretraining on the DRL 20-sec schedule are presented in Table 1. Response rates and percentages of reinforced responses were nearly identical for all Ss; in addition, the percentages were in close agreement with results from previous studies using this schedule (cf. Kramer \& Rilling, 1970).

Daily response totals for each $S$ during the 10 days of OT or ET are presented in Table 2.

A 2 (groups) by 10 (days) repeated-measures ANOVA was performed on the data in Table 2 . The main effect of groups was found to be quite significant $(F=31.23$, $\mathrm{df}=1 / 4$, $p<.01)$, which indicates that the OT Ss emitted fewer responses than the ET Ss. The main effect of days was also significant $(F=35.36$, $\mathrm{df}=9 / 36$,

Table 2

Daily Response Totals During OT or ET

\begin{tabular}{|c|c|c|c|c|c|c|c|c|c|c|c|}
\hline & \multirow[b]{2}{*}{$\mathrm{S}$} & \multicolumn{10}{|c|}{ Days } \\
\hline & & 1 & 2 & 3 & 4 & 5 & 6 & 7 & 8 & 9 & 10 \\
\hline OT & $\begin{array}{r}2 \\
3 \\
14\end{array}$ & $\begin{array}{l}212 \\
138 \\
259\end{array}$ & $\begin{array}{l}15 \\
13 \\
42\end{array}$ & $\begin{array}{l}7 \\
3 \\
8\end{array}$ & $\begin{array}{l}2 \\
2 \\
6\end{array}$ & $\begin{array}{l}4 \\
0 \\
2\end{array}$ & $\begin{array}{l}6 \\
0 \\
0\end{array}$ & $\begin{array}{l}3 \\
0 \\
0\end{array}$ & $\begin{array}{l}2 \\
0 \\
1\end{array}$ & $\begin{array}{l}4 \\
0 \\
2\end{array}$ & $\begin{array}{l}3 \\
0 \\
0\end{array}$ \\
\hline ET & $\begin{array}{l}11 \\
12 \\
16\end{array}$ & $\begin{array}{l}437 \\
250 \\
293\end{array}$ & $\begin{array}{l}137 \\
186 \\
148\end{array}$ & $\begin{array}{r}18 \\
103 \\
100\end{array}$ & $\begin{array}{l}31 \\
25 \\
49\end{array}$ & $\begin{array}{r}10 \\
9 \\
37\end{array}$ & $\begin{array}{r}11 \\
6 \\
44\end{array}$ & $\begin{array}{l}15 \\
13 \\
40\end{array}$ & $\begin{array}{l}91 \\
10 \\
10\end{array}$ & $\begin{array}{r}66 \\
4 \\
9\end{array}$ & $\begin{array}{r}53 \\
4 \\
13\end{array}$ \\
\hline
\end{tabular}

$p<.001)$, reflecting that Ss tended to give fewer responses as training progressed. Finally, a significant Groups by Days interaction $(F=2.73$, $\mathrm{df}=9 / 36, \mathrm{p}<.05$ ) indicates that the groups decreased their responding at different rates; i.e., OT Ss reduced responding very rapidly and were emitting hardly any responses by the fourth day of training, whereas ET Ss decreased responding very gradually and were even emitting a considerable number of responses at the end of training.

The results obtained in the present study extend previous findings of Uhl \& Garcia (1969) and Uhl \& Sherman (1971) by suggesting that the effectiveness of OT vs ET might be closely related to the pretraining schedule of reinforcement and/or the species of Ss used. The previously mentioned "similarity" between DRL schedules and OT might have been responsible for the greater response-elimination effectiveness of $\mathrm{OT}$, although the species variable cannot be discounted.

Investigations are presently being conducted in the Es' laboratory to study the effect of pretraining reinforcement schedules on OT, as well as the relationship between pretraining reinforcement schedules and the particular values of the response-reinforcement and reinforcement-reinforcement intervals during OT.

\section{REFERENCES}

BAER, D. M., PETERSON, R. F., \& SHERMAN, J. A. The development of imitation by reinforcing behavioral similarity to a model. Journal of the Experimental Analysis of Behavior, 1967. 10, 405-416.

KRAMER. T. J., \& RILLING, M. Differential reinforcement of low rates: $A$ selective critique. Psychological Bulletin. 1970, 74, 225-25 4.

LONG, E. R. Additional techniques for producing multiple-schedule control in children. Journal of the Experimental Analysis of Behavior, 1962, 5, 443-455.

LONG E. R. Chained and tandem scheduling with children. Joumal of the Experimental Analysis of Behavior, 1963. 6. $459-472$

MISHKIN M \& WEISKRANTZ, L, Effects of cortical lesions in monkeys on critical nicker frequency. Journal of Comparative \& Physiological Psychology, 1959, 52 , 660-666.

REYNOLDS, G. S. Behavioral contrast. Journal of the Experimental Analysis of Behavior. 1961, 4, 57-;1.

SHERMAN, J. A. Use of reinforcement and imitation to reinstate verbal behavior in mute psychotics. Journal of Abnormal Psychology, 1965, 70, 155-164.

UHL, C. N., \& GARCIA. E. E. Comparison of omission with extinction in response elimination in rats. Journal of Comparative \& Physiological Psychology, 1969, 69, 554-562.

UHL, C. N. \& SHERMAN, W. $O$ Comparison of combinations of omission, punishment, and extinetion methods in response elimination in rats. Journal of Comparative \& Physiological Psychology, $1971,74,59-65$. 